\title{
The Evaluation of the Learning Curriculum of the Aircraft Maintenance Training Organization 147 for Avionic Study Program as a Basis in Meeting the Need of the Aviation Industry
}

\author{
Heni Puspita ${ }^{1,2}$, A. Ana ${ }^{1 *}$, Ike Yuni Wulandari ${ }^{1,2}$, Andriana $^{1,3}$ \\ ${ }^{1}$ Departemen Pendidikan Teknologi Kejuruan, Universitas Pendidikan Indonesia, Jl. Dr. Setiabudhi No. 229 Bdg, Indonesia \\ ${ }^{2}$ Departemen Teknik Elektro FT, Universitas Nurtanio Bandung, Jl. Pajajaran No. 219 Bandung, Indonesia \\ ${ }^{3}$ Departemen Teknik Elektro FT, Universitas Langlangbuana, Jl. Karapitan No.116 Bandung, Indonesia \\ 1'puspitaheni75@upi.edu, ana@upi.edu,ikeyuni@upi.edu, andriana@upi.edu
}

\begin{abstract}
The purpose of this paper was to provide recommendations for setting learning outcomes in the curriculum application of Aircraft Maintenance Training Organization (AMTO 147) as a requirement to produce graduates of the Avionics study program as aircraft maintenance experts. The approach in this research was applied by introducing competency standards required by the aviation industry in accordance with the curriculum standard design framework of the level three diploma program. Competencies that are used as industry references or standards for aircraft maintenance experts are set based on the Civil Aviation Safety Regulations (CASR) Part 147 and CASR Part 65 recommended by the Directorate of Airworthiness and Aircraft Operations, Directorate General of Transportation, Ministry of Transportation of the Republic of Indonesia, and ICAO Annexes 1 (International Civil Aviation Organization). The result of this curriculum design was in the form of a graduate profile accompanied by the description of graduates who have the expertise competency to become aircraft technicians in the field of aviation electronics with basic license $\mathrm{C}$, obtained through the training program of Instrument Electrical Radio Avionics (IERA) in the AMTO 147 curriculum-based learning.
\end{abstract}

Keywords: Aircraft Maintenance Training Organization, Avionics study program, learning outcomes

\section{Corresponding Author}

*Departemen Pendidikan Teknologi Kejuruan, Universitas Pendidikan Indonesia, Jl. Dr. Setiabudi No. 229 Bandung, Indonesia

*ana@upi.edu

\section{Introduction}

Unnur Aero Maintenance Training Center (UAMTC) is an organization that carries out a certification education program for prospective aircraft maintenance experts or aircraft technicians. This organization is in the Faculty of Engineering, University of Nurtanio Bandung. Program development of Aircraft Maintenance Training Organization 147 (AMTO 147) started in 2005 and was approved in 2008, with DGCA Approval Number: 147/0800 (14 March 2008). Since 2008, several study programs in the Faculty of Engineering have gradually started implementing curricula in accordance with the regulations for the implementation of the AMTO program and also the existing regulations in higher education. Understanding the concept of the aviation is important (Anggraeni, Maulidina, Dewi, Rahmadianti, Rizky, Arinalhaq, and Al-Obaidi, 2020; Eftekhari and AlObaidi, 2019).

To meet the needs of aircraft maintenance technicians both at the national and international levels, especially Instrument Electrical Radio Avionics (IERA) training program to get basic license $\mathrm{C}$, the curriculum of the Avionics study program, Faculty of Engineering, Nurtanio University has been tailored to the needs of graduate employers and is in accordance with existing regulations in CASR 147 and Advisory Circular (AC 65-02). The training activities for the IERA program are contained in the Technical Training Procedure Manual (TTPM) (Drown, 1883). On the other hand, with the issuance of Presidential Decree No. 8 of 2012 concerning the Indonesian Qualifications Framework, then in the application of the Avionics study program curriculum for the IERA training program, it is necessary to carry out regular evaluations of the curriculum, as an effort to adapt to the profiles of 
graduates, learning outcomes and teaching materials (Fachrurrozi, 2015).

This research is conducted to obtain profiles of graduates who have competency skills as aircraft technicians in the Avionics field. The urgency of this research is carried out by combining the curriculum design of the AMTO 147 avionics study program into the Indonesian Qualifications Framework (KKNI), which will produce a curriculum design that is suitable to meet the needs of the aviation industry.

Previous research that is relevant to the theme has been conducted. As an example, research on the existence of a gap between academic institutions and the aviation industry (Peksatici and Ergun, 2019). The result of research shows how the different logic or institutional thinking of the aviation industry and aviation management programs creates a gap between the two (Peksatici and Ergun, 2019 ; Ergun and Peksatici, 2019). This gap causes graduates to face difficulties in finding jobs in the aviation industry and also hinders effective collaboration between the industry and academics (Peksatici and Ergun, 2019). Departing from the notion of relevance and curriculum, curriculum relevance is a relationship or anything that is related to all forms of activities that exist in the world of education that can affect students and can achieve educational goals (Hariyanto, 2020).

The AMTO curriculum learning system in Indonesia refers to the standard of CASR part 147 and ICAO Annexes 1. The learning in the AMTO curriculum contains materials on theory and practice that must be taken within \pm 18 (eighteen) months with a total of 3000 hours. This number of hours will be merged into the learning model at the diploma and applied undergraduate levels and into the learning per semester. The 3000-hour learning model refers to the standards applied by the civil aviation regulator in the United States, namely Federal Aviation Administration (FAA). FAA uses the same standards as DGCA in Indonesia, namely CASR 147 and AC 65-02 standards. The module used is of European Aviation Safety Agency (EASA) part 66 (Kulcak, 2006). For the IERA program, the graduates are awarded with basic license category C. In this case the Avionics study program organizes the IERA training program as supporting competencies that must be possessed by aircraft maintenance experts in the field of aviation electronics (avionics).

However, there are no specific studies that focus on the cooperative relationship between the aviation industry and aviation education institutions at the university, tertiary school, and polytechnic levels. It can be concluded that there has been no research on collaboration between the aviation industry and higher education institutions that offer competency certification programs as aircraft maintenance experts. Therefore, it is essential to analyze the current situation or condition and how the transfer of knowledge between the industry and higher education institutions that offer competency certification programs. In addition, it is also significant to identify barriers to the effectiveness of collaboration and knowledge transfer that has been formed in the current conditions. Based on these findings, it is hoped that this research can provide input to both the industry and higher education institutions to achieve effective and sustainable collaboration (Peksatici and Ergun, 2019).

This article describes the competency standards for aircraft maintenance technicians in the field of aviation electronics (avionics) required by the industry into the Indonesian Qualifications Framework. By comparing the length of courses and the level of study in the aviation industry to the Indonesian Qualifications Framework, the closest level associated with aircraft technicians is level five, which is equivalent to a Diploma three qualification in accordance with the Regulation of the Minister of Education and Culture of the Republic of Indonesia Number 49 of 2014 concerning National Higher Education Standards (Kebudayaan, K. P. D, 2014). Researchers try to explain the research problem and the purpose of this research is how an educational institution can meet the qualifications for its graduates as the requirements needed to absorb labor in the aviation industry. While the purpose of this study is to provide recommendations for learning outcomes in the application of the Aircraft Maintenance Training Organization (AMTO 147) curriculum as a requirement to produce graduates as aircraft maintenance experts, especially the Avionics study program. The results objective is to achieve a curriculum design that can be used to obtain profiles of graduates who have the competency skills to become aircraft technicians in the field of aviation electronics (avionics).

\section{Theoretical Framework \\ 2.1 Aviation Safety Laws and Regulations}

The regulations or laws governing the maintenance of civil aircraft in Indonesia are included in the Civil Aviation Safety Regulation (CASR). CASR is a sequence of laws in Indonesia related to aviation, in which the Indonesia is a member of the International Civil Aviation Community (ICAO). CASR is set based on the Minister of Transportation Regulation/Ministerial Decree. It is then a technical or detailed regulation regarding civil aviation safety. CASR is divided into several specific parts such as Part 91 General Operating and Flight Rules, Part 65, Part 135, Part 141, Part 121 Certification and Operating Requirements Domestic, Flag, Supplemental Air Carriers, and Part 147 Aircraft Maintenance Training Organization. All types of aircraft and their feasibility have regulations regulated in CASR. All maintenance and requirements are also included in CASR. Besides, the airworthiness certification process is also regulated in this CASR

\subsection{ICAO Annexes 1}

ICAO annexes 1 is a standard document and recommended practice adopted by international civil aviation organizations as a minimum standard governing personnel licensing. Hence, it can be argued that ICAO annexes 1 becomes the standard and recommended practice for licensing crew members (pilots, flight engineers, and flight navigators), air traffic controllers, aeronautical station 
operators, maintenance technicians, and flight dispatchers, as the International Civil Aviation Convention. The associated training manual provides guidance to states for the coverage and depth of a training curriculum that will ensure confidence in safe air navigation. The ICAO Annexes which is the document standard for international civil aviation as a legal basis contains 19 references (Annexes 119).

The learning used in the implementation of vocational education in the aviation sector refers to the Regulation of the Minister of Transportation of the Republic of Indonesia Number PM 84 of 2017 concerning civil aviation safety regulations section 147 (Civil Aviation Safety Regulations Part 147), which is about Aircraft Maintenance Training Organization. Additionally, the expertise competency refers to Civil Aviation Safety Regulations Part 65 which is about Licensing of Aircraft Maintenance Engineer.

In the provisions of Article 47 of Law Number 1 of 2009 concerning Aviation, it is stipulated that maintenance of aircraft, aircraft engines, aircraft propellers, and their components can only be carried out by maintenance expert personnel who have an aircraft maintenance expert license (aircraft maintenance engineer license). Furthermore, to get an aircraft maintenance expert license (aircraft maintenance engineer license), maintenance personnel must hold a certificate of completion of basic aircraft training (basic aircraft training graduation certificate) or a certificate awarded for completing training from an aircraft maintenance training center organization (aircraft maintenance training organization) which has been certified by the Directorate of Airworthiness and Aircraft Operation of the Directorate General of Civil Aviation, Ministry of Transportation of the Republic of Indonesia. The Basic Certificate in the AMTO program includes Basic Certificate A1.3 for the category of aircraft maintenance experts of Engine Piston Airframe, A1.4 for the category of Turbine Engine Airframe maintenance specialist, and Basic Certificate $\mathrm{C}$ for the category of aircraft maintenance experts in the fields of Instrument, Electrical, Radio, and Avionics.

\section{Method}

The method used in this research is descriptive analysis method in describing problems that occur in the present or ongoing, through an approach by introducing competency standards needed by the industry in accordance with the standard design framework of the diploma program curriculum. The Indonesian Qualifications Framework is officially stipulated by Presidential Regulation No. 8/2012. The explanation regarding the implementation procedures in the education sector is set in the Decree of the Minister of Education and Culture Number 73 of the Year 2013. The final decision mentioned is designed to accommodate the qualifications of attitudes, skills, and knowledge from the various paths that stakeholders can take. The path that is followed involves the fields of education, industry, professionals, and self-taught participants according to the guidelines. These regulations provide proper guidelines for curriculum development in tertiary institutions. The preparation for structuring the Indonesian Qualifications
Framework of higher education curriculum is presented schematically in Figure 1 (Fachrurrozi, 2015).

The stages in this preparation start from the stage of determining the profile of graduates, then the second stage is learning outcomes. The third stage is the material used in learning and the fourth stage is the curriculum structure and learning design. The next step is to determine learning outcomes which consist of four competency parts as illustrated in Table 1. The first and second parts are general attitudes and skills set by the National Higher Education Standards, while the third and fourth sections are specific skills and knowledge, which are formulated by institutions according to the Indonesian Qualifications Framework.

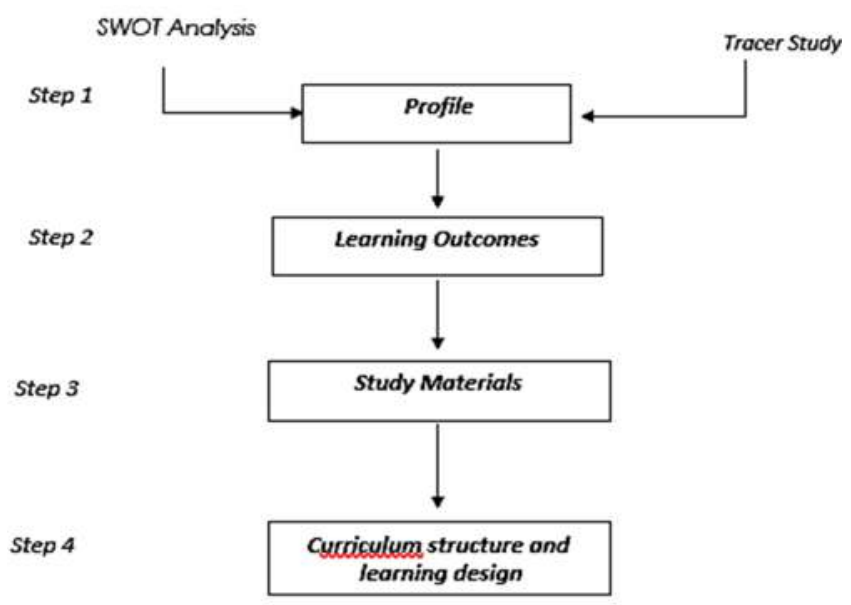

Fig. 1 Higher Education Curriculum Design Process

Table 1. Parameters and descriptions of learning outcomes

\begin{tabular}{|c|l|l|}
\hline No & \multicolumn{1}{|c|}{ Parameter } & \multicolumn{1}{c|}{ Description } \\
\hline 1 & Attitude & $\begin{array}{l}\text { Defined by the National Standards } \\
\text { for Higher Education }\end{array}$ \\
\hline 2 & General Skills & $\begin{array}{l}\text { Determined by the results of the } \\
\text { tracer study, university values and } \\
\text { scientific vision }\end{array}$ \\
\hline 3 & Special Skills & Knowledge \\
\hline 4
\end{tabular}

In the aircraft maintenance industry, competence as a maintenance technician can be obtained through training or learning the AMTO 147 curriculum at an institution or certification body that has received the approval of AMTO 147 from the Directorate of Airworthiness and Aircraft Operations, Directorate General of Civil Aviation, Ministry of Transportation Republic of Indonesia. Figure 2 shows a guideline or regulation that is used as a reference in implementing the AMTO 147 program. The figure explains the scope of the pedagogical or learning basis used which is in accordance with CASR Parts 65 and 147. The AMTO curriculum is designed based on Advisory Circular 65 (AC 65-02) and 147-02. These rules are then made into a guideline or regulation that becomes the basis for conducting AMTO 147 learning. The guideline is called the Technical Training Procedure Manual (TTPM). Every institution that has AMTO 147 approval must have TTPM. The research was conducted in 2017 at the Faculty of Engineering, 
University of Nurtanio Bandung, after obtaining AMTO approval for the avionics training program. The analysis is carried out through a curriculum design process to determine the profile of Avionic study program graduates. From the perspective analysis, there are two different views regarding the profile of graduates for the Avionics study program. The first perspective from a scientific perspective, where the Avionics study program is part of aerospace science for the field of aviation electronics. The profiles of Avionic study program graduates are prepared to become aircraft maintenance technicians equipped with basic license $\mathrm{C}$ competency certifications. The second perspective is the result of tracking graduates which can show a gap between what the industry needs and that provided by educational institutions. This initial analysis is the basis for describing the profiles of Avionic study program graduates. By referring to the Guidelines for Curriculum Development Design, Indonesian Qualifications Framework, and National Higher Education Standards, the profile of Avionic study program graduates must have the competencies required by the aviation industry and meet CASR 147 regulatory requirements for areas of expertise as aircraft maintenance technicians.

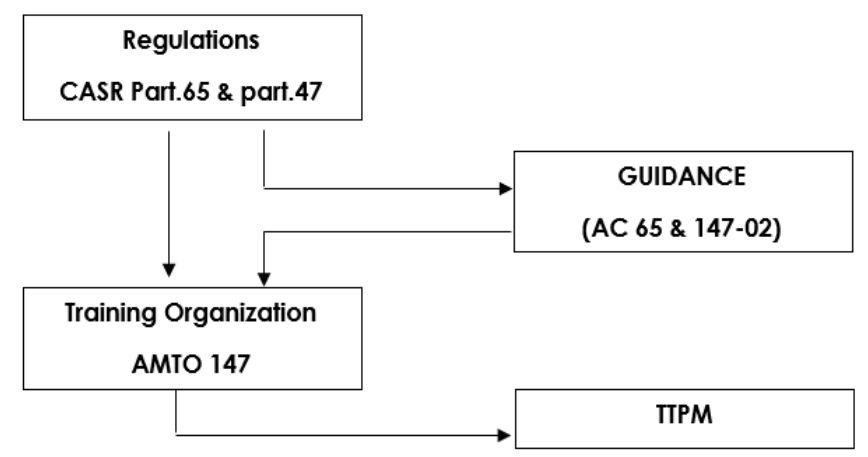

Fig. 2 References in the program implementation of AMTO 147

\section{Results and Discussion}

Based on the method or approach used in this paper, it can be determined that the output profile of new graduates of the Diploma 3 Avionics study program have applied their skill competence to become aircraft technicians in the field of aviation electronics who must have basic license $C$, which can be obtained by attending training or curriculum learning of AMTO 147. Curriculum AMTO 147 for the IERA training program must be taken within 3,000 hours. This number of hours consists of theory and practice. This curriculum design results in the graduate profile accompanied by the profile description. The profile and description are determined and described in Table 2. The next point of discussion is determining learning outcomes. Referring to Table 2, the parameters for general attitudes and skills have been established by the Minister of Education and Culture of the Republic of Indonesia in the National Higher Education Standards (Fachrurrozi, 2015).
Table 2. Output Profile of Avionics Study Program Graduates

\begin{tabular}{|l|l|}
\hline \multicolumn{1}{|c|}{ Graduate Profile } & \multicolumn{1}{c|}{ Description } \\
\hline Aircraft & Aircraft Technician \\
Maintenance & Associate Expert for basic \\
Avionics & and general maintenance of \\
Technician & instrument, electrical, radio \\
& and avionics \\
\hline
\end{tabular}

In this case, the research approach also determines specific skills and knowledge for learning outcomes by referring to the regulations listed in ICAO Annexes 1 and CASR AC 65 until Level 5 of Indonesian Qualifications Framework based on complete learning outcomes of the Avionics study program as described in Table 3.

The flow of curriculum and syllabus preparation of the AMTO 147 course for the IERA training program is shown in Figure 3.

Table 3. Learning Outcomes of Avionics Study Program

\begin{tabular}{|c|c|c|}
\hline No & Parameter & Description \\
\hline 1 & Attitude & $\begin{array}{l}\text { Fear God Almighty } \\
\text { - } \\
\text { Have ethics, high discipline, } \\
\text { and passion for work } \\
\text { Have a pretty good ability in } \\
\text { teamwork } \\
\text { Respect and have a high } \\
\text { tolerance for differences in } \\
\text { culture, norms and customs } \\
\text { Have high motivation and } \\
\text { concern for the environment in } \\
\text { carrying out tasks }\end{array}$ \\
\hline 2 & Common Skills & $\begin{array}{l}\text { Able to complete assignments } \\
\text { using relevant concepts, } \\
\text { theories and methods } \\
\text { Able to conduct research and } \\
\text { community service related to } \\
\text { learning } \\
\text { - Able to manage organizations } \\
\text { in their work } \\
\text { Responsible for work } \\
\text { individually and in groups }\end{array}$ \\
\hline 3 & Special Skills & $\begin{array}{l}\text { - Competent in conducting } \\
\text { analysis, repair and re- } \\
\text { installation of aviation } \\
\text { electronic equipment according } \\
\text { to the procedures in the manual } \\
\text { - Able to carry out aircraft } \\
\text { maintenance activities, in the } \\
\text { field of instrument, electrical, } \\
\text { radio and avionics } \\
\text { Have basic certificate which has } \\
\text { become an industry standard in } \\
\text { aircraft maintenance activities } \\
\text { Have readiness to carry out } \\
\text { learning factory / on the job } \\
\text { training }\end{array}$ \\
\hline 4 & Knowledge & $\begin{array}{l}\text { Able to apply logical, critical, } \\
\text { systematic and innovative } \\
\text { thinking in the context of the } \\
\text { development or implementation } \\
\text { of aviation science and } \\
\text { technology } \\
\text { Understand both the theory and } \\
\text { practice in the field of avionics } \\
\text { to solve the problem }\end{array}$ \\
\hline
\end{tabular}

The curriculum design process starts at the first stage, which is determining the graduate profile for the Diploma 3 
Avionics study program. An analytical perspective in this case is very necessary. From the perspective analysis, there are two different views regarding the profile of graduates for the Avionics study program. The first perspective is from a scientific side where the Avionics study program is considered as a part of aerospace science for the field of aviation electronics. The Avionics program graduates are prepared to become technicians in the field of aircraft maintenance with competency certification basic license C. This competency is obtained through the program IERA training. The structure of the materials in both theoretical and practical learning consists of Mathematics, Physics, Electrical Fundamental, Electronic Fundamental, Digital Technique, Computer Programing, Aircraft Instrument, Material and Hardware, Maintenance Practices, Basic Aerodynamics, Human Factor, Aviation Legislation, Aircraft Aerodynamic Structure and System, Propulsion.

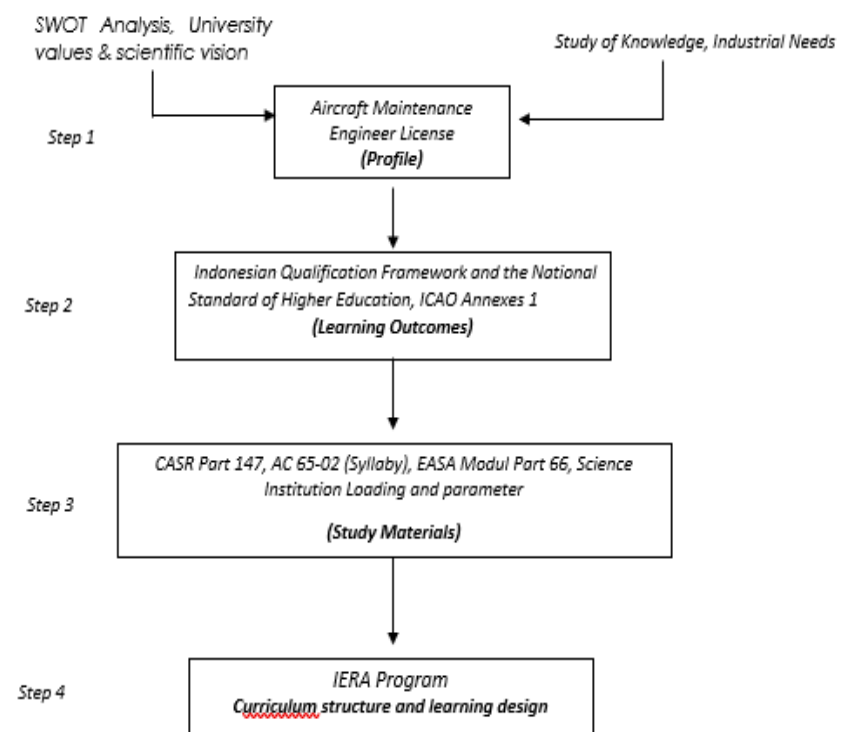

Fig. 3. The Procedure for Preparing the Curriculum and Syllabus for The IERA Training Program Course

The second perspective is the result of tracking graduates which can show a gap between what is needed by industry and what is provided by educational institutions (Peksatici and Ergun, 2019). Trends suggest that this gap will widen in the next five years and are based on data obtained from the viewpoint of the international aviation industry (The 2020 Boeing Pilot and Technician Outlook Projects) that the need for new personnel to support commercial aircraft operations is $2,086,000$. The new personnel requirement consists of 763,000 for pilots, 739,000 for technicians, and 903,000 members of cabin crew. Seeing the opportunity for the substantial need for personnel in the aviation sector is a challenge for higher education institutions in the aviation sector. The number of active technicians will decrease due to retirement. This initial analysis is the basis for describing the profiles of Avionics study program graduates. With reference to the Guidelines for Curriculum Development Design, the Indonesian Qualification Framework, and the National Higher Education Standards, Avionics study program graduates must have the competencies required by the aviation industry and meet the CASR 147 regulatory requirements for their field of expertise as aircraft maintenance technicians. This is also a requirement that the airline industry demands.

Therefore, it is hoped that after graduating from the Diploma 3 of Avionics study program, students will have sufficient skills as Associate Experts and meet the regulatory requirements needed by the industry to be ready to play a direct role in aircraft maintenance in accordance with the vision and mission of the Avionics study program, Faculty of Engineering, Nurtanio University. There are only a few study programs in Indonesia whose graduates are equipped with basic license $\mathrm{C}$ as aircraft maintenance experts of avionics. Over time, a collaboration between study programs of a similar field will continue and a collaboration between the aviation industry and universities in this field is needed, as the means for gathering feedbacks from graduate employers for related study programs. Materials and courses will be discussed by combining the level of study and course topics. Both are drawn from higher education standards and industry needs.

In Figure 3, the procedure for preparing the curriculum and syllabus for the IERA training program in defining the subject matter can be identified. If the learning outcomes have been determined, the next discussion is to decide on learning materials to complete the competency levels. Learning materials, both theoretical and practical, is taken from two parts. The first part is from AC 65-02, which refers to the International Civil Aviation Organization (ICAO) Annexes 1 (Kulyk and Suslova, 2014) and the second one refers to the standard knowledge of aviation electronics (avionics). For the courses, the curriculum using the standard module of EASA part 66 (Usanmaz, 2011) is selected for training aircraft maintenance technicians. EASA module hours are converted to be used by the aviation industry into a semester credit system focusing on both theories and practices by referring to CASR 147 and CASR AC 65-02 regulations which contain the core of specific knowledge and skills that aircraft maintenance technicians must achieve.

However, the learning materials cannot be taught optimally due to several factors that become obstacles during the practice in the field. Especially with regard to the use of learning media both in theory and practice, the learning process has not been fully supported by the technology that continues to develop in the world of aviation. This is a big enough challenge for institutions to be able to adapt technological advances that can be used as the media for understanding the theory and practice, in preparing graduates as aircraft maintenance technicians. In addition, the AMTO curriculum for the designed IERA training program still carries local curriculum content. It requires a good strategy to convert AMTO hours into a semester credit system. Finally, in formulating types of courses, the Avionics Study Program curriculum for the IERA training program uses standard modules of aircraft maintenance technician course for the European Aviation Safety Agency 
(Dalkilic, 2017; Adamčík, 2007). This choice is taken from the standards used by the largest aircraft maintenance industry in Indonesia as a sample. The design of the Avionics study program curriculum for the IERA training program is carried out by converting the EASA part 66 module hours used by the industry into a semester credit system, both theoretical and practical.

\section{Conclusion}

The conclusions obtained from this study can be a reference for educational institutions in fulfilling the qualifications of their graduates as the requirements needed to absorb labor in the aviation industry. From the results of the AMTO 147 curriculum design for the IERA training program, it can be seen that the number of hours of training or learning that students have to take is 3,000 hours.

\section{References}

Adamčík, F. (2007). University study of aviation specialists at the faculty of aeronautics of the technical university of Košice. Aviation, 11(4), 36-39.

Anggraeni, S., Maulidina, A., Dewi, M. W., Rahmadianti, S., Rizky, Y. P. C., Arinalhaq, Z. F., and Al-Obaidi, A. S. M. The Deployment of Drones in Sending Drugs and Patient Blood Samples COVID-19. Indonesian Journal of Science and Technology, 5(2), 18-25.

Dalkilic, S. (2017). Improving aircraft safety and reliability by aircraft maintenance technician training. Engineering failure analysis, 82, 687-694.

Drown, T. M. (1883). Technical training. Journal of the Franklin Institute, 116(5), 329-354.

Eftekhari, S., and Al-Obaidi, A. S. M. (2019). Investigation of a cruising fixed wing mini unmanned aerial vehicle performance optimization. Indonesian Journal of Science and Technology, 4(2), 280-293.

Fahrurrozi, A. (2015). Aeronautical engineering diploma curriculum program for basic aircraft maintenance to answer the demand of aircraft maintenance technician in Indonesia. Jurnal Teknologi, 77(23), 83-87.

Hariyanto, E. (2020). The relevance of airframe powerplant competencies in Bina Dhirgantara vocational high school with the aviation industry. Journal of Physics: Conference Series, 1446(1), 012072.

Kulcák, L. (2006). University education for civil aviation in the $\mathrm{Cr}$ according to European standards. Aviation, 10(4), 2529.

Kulyk, M., and Suslova, G. (2014). Integration of the ICAO Training Institute into the international education network. Aviation, 18(2), 104-108.

Peksatici, Ö., and Ergun, H. S. (2019). The gap between academy and industry-A qualitative study in Turkish aviation context. Journal of Air Transport Management, 79, 101687.

Usanmaz, O. (2011). Training of the maintenance personnel to prevent failures in aircraft systems. Engineering Failure Analysis, 18(7), 1683-1688. 